\title{
Data Materiality and Social Agency
}

\author{
David Graham ${ }^{1}$ \\ 1 University College Dublin
}

Funding: The author(s) received no specific funding for this work.

Potential competing interests: The author(s) declared that no potential competing interests exist.

\begin{abstract}
In the data-rich environment of the $21^{\text {st }}$ century, it has become critical to understand the implications of data materiality and the impact it has on social agency. With the recent passage and introduction of legislation, specifically in the United States, targeted at marginalised communities, it behooves us to take a deeper look at the role of data materiality in the suppression of data agency as well as remedies of the same.
\end{abstract}

In the data-rich environment of the $21^{\text {st }}$ century, it has become critical to understand the implications of data materiality and the impact it has on social agency. With the recent passage and introduction of bills of law, specifically in the United States, specifically targeted at marginalised communities, it behooves us to take a deeper look at the role of data materiality in the suppression of data agency as well as remedies of the same.

The principles of materiality that are being focused on here combine the teleological perspectives of both social and data sciences. "Data Materiality" is centered on the ethereal nature of data as a social artifact and its implications for social agency to a people group. In the application we are discussing here, the view is towards Texas Senate Bill 8, as a cornerstone example of a data-mining bill masquerading as a social action, promotes the ideas of civilian reporters documenting, researching, and providing, through judicial process, the names, identities, and information of individuals closely coupled to persons securing reproductive health measures. Implicit in this process is the idea that data about these people becomes "weaponized" and litigated with data curation to occur as a part of the legal discovery process. What is most meaningful in this circumstance is the intense focus on the social action of individuals who are ancillary to the medical process: family members, transportation providers, medical professionals, and others who may have been or were aware of the help being sought. The principle mechanism of this focus is on "whistleblower reporting" and collection through a form hosted on a public-facing website.

Data becomes the fulcrum with which social agency is decided; either in a participatory manner or involuntarily. In the aforementioned situation, participation is unwanted. How does one, then, act to take control over their social agency in such a world?

Data is only valuable to those who can curate, incorporate, and understand its values. The materiality 
theory applied here suggests that data, as a cultural artifact, has permanence beyond its typical ethereal state. To counter the value, then, agency would demand that in the face of data being given unprecedented importance, devaluing it by creating a glut of data with dubious quality would remove its primacy in the repression of a marginalised group. As a secondary effect, the denial of information gathering services would also destablisize the infrastructure used to collect data for use. By removing key components of this data economy, the people group most affected by its collection and valuation would increase their agency to operate in society as they expect, not as proscribed by antagonistic legislation. 